\title{
Improving Hepatitis B Vaccine Efficacy in End-Stage Renal Diseases Patients and Role of Adjuvants
}

\author{
Mohammad Hossein Somi ${ }^{1}$ and Babak Hajipour ${ }^{2}$ \\ ${ }^{1}$ Liver and Gastroenterology Research Center, Tabriz University of Medical Sciences, \\ Tabriz, Iran \\ ${ }^{2}$ Urmia University of Medical Sciences, Urmia, Iran \\ Correspondence should be addressed to Babak Hajipour, hajipourb@yahoo.com
}

Received 18 June 2012; Accepted 1 August 2012

Academic Editors: G. Barbaro, A. Nakajima, W. Vogel, and C. Y. Yeung

Copyright ( $) 2012$ M. H. Somi and B. Hajipour. This is an open access article distributed under the Creative Commons Attribution License, which permits unrestricted use, distribution, and reproduction in any medium, provided the original work is properly cited.

Hepatitis B virus (HBV) infection is a serious global health problem. The prevalence of viral hepatitis is higher in dialysis patients than in the general population because of the opportunity for exposure during the dialysis procedure. Immunization is the most effective way to prevent transmission of hepatitis B virus (HBV) and hence the development of acute or chronic hepatitis B. It is well established that patients with end-stage renal disease including dialysis-dependent patients, have an impaired immune response to hepatitis B vaccine. End stage renal diseases (ESRD) patients have lower seroconversion rates compared with the subjects with intact renal function. Moreover, even after the completion of vaccination schedule anti-hepatitis B (anti-HBs) titers of responder dialysis, patients are low and decline logarithmically with time. The impaired efficacy of HBV vaccine in patients with ESRD has been attributed to numerous factors such as immune compromise because of uremia and some other factors. One approach to improve the immunogenicity of existing HBV vaccines is adjuvantation, and it's very important to find more effective adjutants for improving $\mathrm{HBV}$ vaccine efficacy. In this paper we have a brief review on recently known new ways for improving HBV vaccine efficacy.

\section{Hepatitis B Virus (HBV)}

Hepatitis B virus (HBV) is an important cause of serious liver disease including acute and chronic hepatitis, cirrhosis, and primary hepatocellular carcinoma. Liver disease is a significant cause of morbidity and mortality in patients on maintenance dialysis, with hepatitis HBV infection among the important etiologies. People under going chronic dialysis are at high risk for HBV infection. People with chronic HBV infection can transmit the infection for many years. There are probably more than 400 million people worldwide with chronic hepatitis B infection which is responsible for 520,000 deaths and 470,000 cases of hepatocellular carcinoma (HCC) annually [1]. More than $75 \%$ of these live in the Asia-Pacific region, with high numbers also residing in Africa and the Amazon basin. In areas of high endemicity, the lifetime infection rate is above $50 \%$, and more than $8 \%$ of the populations are chronic carriers [2]. Infection in such regions is typically acquired in childhood, either horizontally from other children or perinatally from maternal carriers. By contrast, parenteral transmission is common in Australia, and fewer than $2 \%$ of the populations are chronic $\mathrm{HBV}$ carriers [3].

\section{Hepatitis B and Hemodialysis Patients}

The prevalence of HBV infection is now low within dialysis units of the developed world with chronic HBsAg seropositivity ranging from $0 \%$ to $10 \%$ in patients on long-term dialysis. Recently, a study sample from the dialysis outcome and practice patterns study, a cross-sectional study of 8615 adult haemodialysis patients from 308 dialysis facilities in Western Europe and the United States, has reported that the prevalence rates of chronic HBV infection on regular dialysis range between $0 \%$ and $7 \%$ [4]. The majority of facilities (78.1\%) had an HBsAg seroconversion rate of 0 per 100 patient-years [4]. 
The epidemiology of HBV among dialysis patients in the less-developed world is not well known. There are scattered reports, typically single-center surveys, with rates of chronic HBsAg carriers ranging between $2 \%$ and $20 \%$ [5-13]. The higher HBV infection rates within dialysis units in the developing world can be attributed to several factors, an important one being the higher background prevalence of HBV in the general population. Also playing a prominent role are difficulties following infection control strategies against HBV such as "standard" precautions, routine hemodialysis precautions, cohorting of HBsAg-positive patients by rooms, machines and staff, vaccination against $\mathrm{HB}$ virus, and blood screening; these deficiencies are often attributable, at least in part, to a lack of financial and other resources $[14,15]$.

Over the past few decades, there has been a substantial decrease in the incidence of hepatitis B virus (HBV) infection in hemodialysis patients, probably attributable to screening of blood donors, a decline in blood transfusion requirements with increased erythropoietin use, and authoritative guidelines relating to infection control and vaccination. Despite this progress, hemodialysis patients remain at increased risk of acquiring HBV because of increased exposure to blood products, shared hemodialysis equipment, frequent breaching of skin, immunodeficiency, and continuing high prevalence rates of HBV infection among hemodialysis populations.

It is well established that patients with end-stage renal disease (ESRD), whether dialysis dependent or not, have an impaired immune response to hepatitis B vaccine [15]. ESRD patients have lower seroconversion rates compared with the subjects with intact renal function. Moreover, even after the completion of vaccination schedule anti-hepatitis B (antiHBs) titres of responder dialysis, patients are low, and decline logarithmically with time [15]. Recent reports [16, 17] have demonstrated a low but not inconsequential frequency of hepatitis B virus (HBV) infection in dialysis facilities in the developed countries. Prevalence and incidence rates of $\mathrm{HBV}$ are higher within the dialysis units of the developing world [18-21]. Outbreaks of HBV infection among the haemodialysis (HD) patients continue to be recognized in the industrialized countries [22]. The control of spread of HBV infection within dialysis units of developed world has been a milestone in the management of ESRD [15]. The impaired efficacy of HBV vaccine in patients with ESRD has been attributed to numerous factors such as immune compromise because of uraemia, age [23], gender [24], body weight [25], nutritional status [26], seropositivity for antibody against hepatitis C virus (HCV) [27] or human immunodeficiency virus (HIV) [28], low serum albumin [29], possession of the major histocompatibility complex haplotype HLA-B8, SCOI, DR3 [30], and blood transfusion history [31]. The failure to complete a full course of HBV vaccination also impairs the immunization response $[32,33]$. Although acute infection tends to be mild and asymptomatic in dialysis patients, up to two-thirds may progress to chronic carriage, with significant risk of chronic liver disease, premature death from cirrhosis or liver cancer, and nosocomial transmission within hemodialysis units [34-36].

\section{Epidemiology of HDV among Hemodialysis Patients}

Twenty-five years ago Rizzetto et al. [37], while examining liver biopsies from individuals infected with HBV, discovered by immunofluorescence a previously unrecognized nuclear antigen that was subsequently shown to be a specific marker of a novel human pathogen, HDV.

The clinical association with HBV results from the fact that HDV is a defective virus that requires a helper function provided by HBV or other hepadnaviruses [38]. In association with HBV, HDV produces significantly more severe illness than HBV alone [39]. HDV is now well known to induce a spectrum of both acute and chronic liver diseases [40]. Individuals having HBV-HDV coinfection may have more severe acute disease and higher risks of fulminant hepatitis, cirrhosis, and hepatocellular carcinoma (HCC) than those having HBV infection alone [41, 42].

HDV infection has high prevalence in Asia pacific region. Countries like Pakistan and Iran have shown an increase in HDV prevalence over a period of time. Other countries and regions like China, Turkey, Australia, Japan, India, and Taiwan, some of which had very high HDV prevalence in the past, have shown a decline in the incidence, but high prevalence persists in some. Intravenous drug abusers, homosexual men and women, prostitutes, and people on hemodialysis are the groups with very high HDV prevalence [43]. In 2000, 1.3\% of blood donors positive for HBsAg and 25.2\% of HBsAg-positive hemodialysis patients were found to be anti-HDV positive [44].

In our previous research the seroprevalence of HDV was $9.3 \%$ among HBV positive patients. This rate was significantly higher after reaching 40 years of age. The rate was $12.7 \%$ in patients with chronic hepatitis B and $4.7 \%$ in patients with inactive hepatitis B [45].

\section{The Hepatitis B Vaccine}

In the 1970s, Krugman observed that HBsAg was immunogenic, and that anti-HBs antibodies were protective against hepatitis B [46]. A first-generation vaccine was subsequently developed, consisting of HBsAg extracted by plasmapheresis from HBV carriers, and then inactivated [47]. Safety data are comprehensive. A large prospective trial has shown the vaccine to be safe and well tolerated [48].

Currently available hepatitis B (HB) vaccines have an excellent safety and immunogenicity profile, conferring seroprotection in more than $95 \%$ of the vaccinated population [49]. Nevertheless, certain population subgroups, such as some healthy people and immunocompromised subjects, do not respond adequately to vaccination. Among these groups, end-stage renal disease (ESRD) patients, comprising pre- and hemodialysis patients, are considered at high risk for $\mathrm{HB}$ infection due to cross-contamination to patients via environmental surfaces, disposables, or equipment during the process of hemodialysis [50-53]. Once infected, about $60 \%$ of hemodialysis patients will become chronic carriers of the $\mathrm{HB}$ surface antigen (HBsAg), increasing the risk of contamination for other hemodialysis patients, 
medical personnel, and family members [54] and leading to significant logistic and practical difficulties, including provision for separate medical devices and staff [55]. In a research by Sorkhi et al., patients received 4 microg vaccine intramuscularly at 0,1 , and 6 months. All were negative for $\mathrm{HBV}$ infection markers ( $\mathrm{HBcAb}, \mathrm{HBsAg}$, and $\mathrm{HBsAb}$ ). Of 62 patients, $53(85.5 \%)$ responded to vaccination, and $26(49.1 \%)$ were high responders [56]. In a research by Miłkowski et al. the efficacy of HBV vaccination was $77.5 \%$ in hemodialysis patients [57].

Attempts to overcome the impaired immune response in hemodialysis patients have produced mixed results. An increased dose strategy with additional injections was found to be necessary to improve the response rate in these subjects. Currently a 0-, 1-, 2-, and 6-month schedule with double doses hepatitis B surface antigen $(2 \times 20 \mu \mathrm{g} \mathrm{HBsAg})$ of commercially available $\mathrm{HB}$ vaccine is recommended in hemodialysis patients, with regular monitoring of antibody levels to ensure that antibody concentrations remain above the protective level of $10 \mathrm{mIU} / \mathrm{mL}$ [58]. Several strategies to enhance the immune response have been proposed among which are novel adjuvant systems. Adjuvants are thought to improve immune responses by (a) causing depot formation at the injection site; (b) increasing the interaction between immunogen and macrophage; (c) improving antigen presentation to T cells [59]. Very few vaccine adjuvants have been licensed for prophylaxis in human. Among them alum (aluminum salts) has been widely used for more than 70 years and until recently represented the only adjuvant approved in the United States. Oil in water emulsions (MF59 and AS03) is licensed for adjuvanted influenza vaccines in Europe. AS04, a combination adjuvant composed of monophosphoryl lipid A (MPL) adsorbed to alum, is approved for HBV and human papilloma virus (HPV) vaccines in Europe and has been recently licensed in the USA. This section will focus on the new adjuvants used for improving HBV vaccination efficacy in ESRD patients $[60,61]$.

\section{Recombinant Interferon- $\alpha 2 b$}

Among the different cytokine candidates containing adjuvant activity, interferons $(\alpha, \beta, \gamma)$ deserve special attention in view of their known effects promoting cellular and humoral immune responses $[62,63]$. In particular, studies in mouse models have pointed out that interferon (IFN) $\alpha$ potently enhanced both $\mathrm{T}$ cell and antibody responses, augmenting the production of all subclasses of IgG, and induced longterm antibody production and immunological memory after a single injection of soluble protein antigen [64]. Furthermore, results also obtained in mice have shown that (i) dendritic cells (DCs) are target cells for the adjuvanticity of IFN- $\alpha$ in vivo [50]; (ii) the administration of this cytokine as an adjuvant of the human influenza vaccine results in a remarkable enhancement of vaccine immunogenicity [65]. Of note, IFN- $\alpha$ has been found to strongly induce the differentiation and activation of both mouse and human DCs [66]. Moreover, in chimeric mouse models susceptible to human immunodeficiency virus (HIV) infection, a strong protective immune response has been demonstrated after vaccination with inactivated-virus-pulsed DCs generated from monocytes in the presence of IFN- $\alpha$ [67]. Considering all these studies in animal models, we now know that the most effective way of using IFN- $\alpha$ as a vaccine adjuvant is when this cytokine is injected together with, or in close proximity to, antigens in order to allow optimal interactions with IFN-primed DCs, thus providing a new rationale for using IFN- $\alpha$ as a vaccine adjuvant in humans.

In conclusion, the use of IFN as an immune adjuvant to HBV vaccine is safe and achieves an earlier and higher seroprotection rate improving Th1-dependent immune response in HD patients, suggesting that a similar strategy of IFNadjuvanted HBV vaccination could be useful in other populations of $\mathrm{HBV}$ vaccine hyporesponders, such as cirrhotics and liver transplant recipients, who are at high risk of acquiring HBV infection [68].

\section{GM-CSF}

There is growing evidence that granulocyte macrophage colony-stimulating factor (GM-CSF) enhances the immune response to vaccines direct against both infectious agents and various cancers [69]. GM-CSF has a variety of effects on immune responses, and coimmunization with GM-CSF has been shown to increase the antibody response and to enhance the proliferative response of T cells [70]. The efficacy of GMCSF as adjuvant to hepatitis B vaccine has been object of several clinical trials conducted in healthy subjects, patients with end-stage renal disease, and HIV-infected patients [7173].

Early reports have found a very promising effect of GMCSF as an adjuvant to HBV vaccine [71]. Subsequently, the efficacy of this approach has been widely explored, and a number of controlled and uncontrolled clinical trials have evaluated the adjuvancy properties of GM-CSF in combination with $\mathrm{HBV}$ vaccine [73].

The vaccine adjuvant properties of GM-CSF are based on a variety of effects on immune responses, which include macrophage activation, increasing MHC class II antigen expression, enhancing cell maturation and migration, enhancing memory cell generation via $\mathrm{T}$ and $\mathrm{B}$ cell activation, and inducing localized inflammation at the site of injection [74]. However, the exact mechanism by which GM-CSF may improve the immune response to HBV vaccination is unclear and deserves further research. Of note, a study investigating the effect of GM-CSF in primary nonresponding hemodialysis patients has shown a decrease in the antigen-presenting capacity of peripheral blood mononuclear cells and in the number of circulating dendritic cells [73].

The GM-CSF dosages ranged from 20 to $300 \mu \mathrm{g}$, and these differences have been described as a possible explanation for discrepancies of results obtained in different studies. Actually, using logistic regression Cruciani et al. have shown that the treatment effect was dependent on GM-CSF dose. Predicted response rate strongly increased with increase in GM-CSF dosage. Data from studies conducted in hemodialysis patients show that in individuals who have responded to the vaccine GM-CSF increased the anti-HBs titers. In fact, 
the standardized mean difference of antibody titers at the end of vaccination cycle was statistically significant. Since the extent of the maximal antibody response has been correlated with the persistence of protective antibody over time, it may be supposed that GM-CSF provides a lasting protection in renal failure patients responding to immunization $[75,76]$.

\section{HB-AS04}

An adjuvanted HBV vaccine HB-AS04 (FENDrix; GlaxoSmithKline (GSK) Biologicals, Rixensart, Belgium) was licensed in Europe in 2005 for active immunization against HBV for patients with renal insufficiency (including prehemodialysis and hemodialysis patients) aged over 15 years [77]. HB-AS04 consists of recombinant hepatitis B surface antigen (HBsAg) formulated with aluminum phosphate and monophosphoryl lipid (MPL), a purified, detoxified derivative of the lipopolysaccharide molecule of the bacterial wall of Salmonella minnesota [78]. Results of clinical studies show HB-AS04 to elicit higher and more persistent levels of anti-HBs antibodies than double doses of a conventional recombinant $\mathrm{HBV}$ vaccine when administered according to a 0-, 1-, 2-, and 6-month schedule [79].

HB-AS02 is an adjuvanted HBV vaccine containing recombinant $\mathrm{HBsAg}$ formulated with AS02 instead of AS04. AS02 is an oil-in-water emulsion-based adjuvant system consisting of MPL and QS21, a highly purified immunostimulant extracted from the bark of the South American Quillaja saponaria tree [77]. HB-AS02 does not contain any aluminum salt and is formulated without any preservative. HB-AS02 administered according to a 0-, 1-, and 10-month schedule has been shown to elicit strong and persistent antibody responses against HBsAg in healthy adult volunteers [80]. All subjects were seroprotected after two vaccine doses, with a geometric mean anti-HBs antibody concentration (GMC) of approximately $8000 \mathrm{mIU} / \mathrm{mL}$ [80].

\section{Comparison of AS02 and ASO4}

In summary, a three-dose primary course of the adjuvanted $\mathrm{HBV}$ vaccine HB-AS02 induces more rapid, enhanced, and persistent protection in pre-dialysis, peritoneal dialysis, and hemodialysis patients than a four-dose primary course of HB-AS04 (FENDrix), an adjuvanted HBV vaccine licensed in Europe for use in patients with renal insufficiency [77]. The higher postvaccination GMCs for anti-HBs antibodies and the greater proportion of subjects achieving anti-HBs antibody concentrations of $\mathrm{X} 100 \mathrm{mIU} / \mathrm{mL}$ after vaccination with HB-AS02 suggest that duration of protection is also likely to be enhanced, potentially affording further reductions in the need for booster doses in this at-risk population. Such adjuvanted hepatitis $\mathrm{B}$ vaccines may also have clinical utility in other categories of immunocompromised patients [81].

\section{Erythropoietin (EPO)}

Inhibition of erythropoiesis is the main cause of renal anaemia in ESRD patients, and the leading causes of impaired erythropoiesis are inadequate intrinsic EPO production and iron deficiency [82]. With the goal of corrected renal anaemia, recombinant human erythropoietin ( $\mathrm{rHuEPO}$ ) and intravenous (IV) iron replacement therapy are commonly used in ESRD patients. Because of their impaired immune system, patients with renal failure have a suboptimal response to the hepatitis B vaccine [83]. Many authors had tried to search for the factors influencing the antibody response to the hepatitis $\mathrm{B}$ vaccine in dialysis patients. There is much evidence suggesting that $\mathrm{rHuEPO}$ may influence the immune response because of its effects on the cells of the humoral and cellular immune system [84]. Besides, iron is known to negatively affect cell-mediated immune effector mechanisms directed against invading microorganisms and tumour cells [85]. In conclusion, Liu et al.'s study reveals that $\mathrm{rHuEPO}$ treatment improves the hepatitis B vaccination response, and the immune response is positively correlated with the dose of rHuEPO treatment during the vaccinated period in ESRD patients. More importantly, concomitant IV iron therapy will attenuate anti-HBsAg titres after quadruple hepatitis $\mathrm{B}$ vaccinations in dialysis patients who are undergoing rHuEPO therapy. In particular, decreased anti-HBsAg titres in the seroconversion group were found [86].

\section{Levamisole}

Levamisole is an immunostimulant that both in vivo and in vitro has been reported to increase natural killer cells and activated $\mathrm{T}$ cells by enhanced production of, or eliciting synergistic effect of, interleukin (IL)-1 [87], IL-2 [88], IL18 , and IL-12 [89]. It has also been reported that levamisole can cause a 3 -fold increase in production of interferon $\alpha / \beta$ by adherent nonparenchymal liver cells [90]. Studies have reported the effects of levamisole in immunotherapeutic combinations for infectious diseases such as leprosy [91], brucellosis [92], chronic HBV infection [93], and influenza [94]. Other studies have reported on levamisole used as adjuvant therapy for some malignant and preneoplastic tumors $[88,95]$. However, few studies have found promising results, especially in the treatment of chronic HBV infection $[96,97]$.

The results from a meta-analysis by Alavian and Tabatabaei [98] suggested that oral levamisole administered as an adjuvant to $\mathrm{HBV}$ vaccine increased seroprotection in these patients with ESRD who were undergoing dialysis. Large randomized clinical trials (RCTs) with longer durations of followup are needed to support this finding as there is a study by Sali et al. [92] levamisole did not increase HB vaccine efficacy significantly.

\section{Hepatitis B and A Combined Vaccination}

Recent reports suggest that combined vaccination of hepatitis B and hepatitis A may improve immunogenicity to hepatitis B in healthy individuals. In 1 study that compared the geometric mean of anti-HBsAg titers at month 6, patients receiving the combined vaccine showed a statistically significant higher response than with monovalent vaccines [99], other studies also reflect the same trend at varying points in the vaccination series [100]. 
In comparison to healthy persons, who have a reported $89 \%$ seroprotection rate at month 3 and $90 \%-95 \%$ at month 7 with standard dosing, seroprotection rates in this study population were much lower [101]. This is not surprising because chronic renal failure often is associated with compromised immune function [102]. However, in our population, the seroprotection rate in our control group also was lower compared with previous studies of hemodialysis patients, in which median seroprotection rates of $64 \%-86 \%$ were reported [103]. There are a number of factors that decrease response to hepatitis B vaccination, including sex, age, HLA type, and nutritional status. 28 of these older age and male sex may have had a significant impact in decreasing seroconversion rates in this study [104].

Vaccination against hepatitis A virus in dialysis patients is not routinely performed because it is neither associated with hemodialysis therapy nor transmitted through parenteral mechanisms [105]. There is also no documented evidence for adverse events associated with vaccination of patients previously immune to hepatitis A virus, although these patients may experience a postvaccination increase in the geometric mean titer of antihepatitis A virus antibody.

In conclusion, there was a statistically significant difference in seroprotection between the 2 groups at the completion of the vaccination series. Vaccination of hemodialysis patients with a combined hepatitis $A$ and hepatitis $B$ regimen may be more effective than hepatitis $B$ monovalent vaccine in providing seroprotection against hepatitis B virus [106]. But as our previous report HAV seroprevalence is high in the society (97.3\%) and chronic liver diseases patients (96.5\%) in Iran [107], so combined vaccination of HAV and HBV may not be effective, and we recommend that before HAV combined vaccination as adjuvant, it is better to measure HAV antibody, as if it is possible combined vaccination will have no additional effect in stimulating immune system.

\section{Dermal or Muscular Route of Administration?}

To improve vaccination response, it is advised that patients be vaccinated as early in the course of renal disease as possible, using double-vaccine dose [108] and a 4- rather than 3-dose schedule. Other strategies that have shown variable success include the addition of adjuvants or immunostimulants [109]. Repeated intradermal (ID) administration of low doses of recombinant HBV vaccine has also been tried in small studies [110] with suggested benefit. However, current guidelines 2 advise against ID vaccination, claiming insufficient data to support this practice.

Barraclough et al. study is the largest study to date comparing ID with intramuscular (IM) HBV vaccination in hemodialysis patients nonresponsive to a primary HBV vaccination course. Study participants were reflective of dialysis patients in the developed world, making our results generalizable to this patient group. ID vaccination was well tolerated and convenient. They clearly show that ID vaccination afforded improved seroconversion, greater peak antibody titers, and similar duration of persistence of protective antibody titers. Although it is appropriate for
IM HBV vaccination to remain the route of choice for primary vaccination in light of greater experience, proven efficacy, and ease of administration; our data suggest that ID vaccination provides a useful method for overcoming the immune deficit in the problematic group of patients nonresponsive to a primary vaccination course. A large randomized controlled trial is required to confirm their findings and the superiority of ID HBV vaccination in this setting [111].

\section{Conclusion}

It is very important to find more effective ways to prevent HBV infection in the society especially immunosuppressant and hemodialysis patients. However, infection rates are still unacceptably high, and further work is required. It is recommended that for ESRD patients double-dose vaccination be used at first as soon as possible probably before dialysis, and if it would not be effective; use adjuvanted vaccines for achieving better response, but there is a long way for finding better and more effective adjuvants in which have less side effects beside its protective properties.

\section{References}

[1] K. Inoue, O. Ogawa, M. Yamada, T. Watanabe, H. Okamoto, and M. Yoshiba, "Possible association of vigorous hepatitis $\mathrm{B}$ virus replication with the development of fulminant hepatitis," Journal of Gastroenterology, vol. 41, no. 4, pp. 383387, 2006.

[2] M. Kane, "Global programme for control of hepatitis B infection," Vaccine, vol. 13, no. 1, pp. S47-S49, 1995.

[3] M. Edey, K. Barraclough, and D. W. Johnson, "Review article: Hepatitis B and dialysis," Nephrology, vol. 15, no. 2, pp. 137$145,2010$.

[4] A. Covic, L. Iancu, C. Apetrei et al., "Hepatitis virus infection in haemodialysis patients from Moldavia," Nephrology Dialysis Transplantation, vol. 14, no. 1, pp. 40-45, 1999.

[5] Vladutiu, Cosa, Neamtu et al., "Infections with hepatitis B and $\mathrm{C}$ viruses in patients on maintenance dialysis in Romania and in former communist countries: yellow spots on a blank map?" Journal of Viral Hepatitis, vol. 7, no. 4, pp. 313-319, 2000.

[6] L. L. Lewis-Ximenez, J. M. Oliveira, L. A. C. Mercadante et al., "Serological and vaccination profile of hemodialysis patients during an outbreak of hepatitis B virus infection," Nephron, vol. 87, no. 1, pp. 19-26, 2001.

[7] A. Rehman, A. Mazhar, M. A. Sheikh, M. M. Naeem, and I. A. Bhatti, "Hepatitis B surface antigen carrier rate in unvaccinated and vaccinated children with thalassaemia major at Bahawal Victoria Hospital, Bahawalpur, Pakistan," Eastern Mediterranean Health Journal, vol. 18, no. 4, pp. 378-381, 2012.

[8] A. Aghakhani, M. Banifazl, A. A. Velayati, A. Eslamifar, and A. Ramezani, "Occult hepatitis B virus infection in hemodialysis patients: a concept for consideration," Therapeutic Apheresis and Dialysis, vol. 16, no. 4, pp. 328-333, 2012.

[9] K. Boulaajaj, Y. Elomari, B. Elmaliki, B. Madkouri, D. Zaid, and N. Benchemsi, "Prevalence of hepatitis C, hepatitis B 
and HIV infection among haemodialysis patients in IbnRochd university hospital, Casablanca," Nephrologie et Therapeutique, vol. 1, no. 5, pp. 274-284, 2005.

[10] Z. Abbas and A. R. Siddiqui, "Management of hepatitis B in developing countries," World Journal of Hepatology, vol. 3, no. 12, pp. 292-299, 2011.

[11] R. C. Ferreira, S. A. Teles, M. A. Dias et al., "Hepatitis B virus infection profile in hemodialysis patients in Central Brazil: prevalence, risk factors, and genotypes," Memorias do Instituto Oswaldo Cruz, vol. 101, no. 6, pp. 689-692, 2006.

[12] F. Yakaryilmaz, O. Alp Gurbuz, S. Guliter et al., "Prevalence of occult hepatitis B and hepatitis C virus infections in Turkish hemodialysis patients," Renal Failure, vol. 28, no. 8, pp. 729 735, 2006.

[13] Centers for Disease Control, "Recommendations for preventing transmission of infections among chronic hemodialysis patients," Morbidity and Mortality Weekly Report, vol. 50, no. RR-5, pp. 1-43, 2001.

[14] F. Fabrizi, P. Messa, and P. Martin, "Hepatitis B virus infection and the dialysis patient," Seminars in Dialysis, vol. 21, no. 5, pp. 440-446, 2008.

[15] P. Martin and L. S. Friedman, "Chronic viral hepatitis and the management of chronic renal failure," Kidney International, vol. 47, no. 5, pp. 1231-1241, 1995.

[16] D. A. Goodkin, E. W. Young, K. Kurokawa, K.-G. Prütz, and N. W. Levin, "Mortality among hemodialysis patients in Europe, Japan, and the United States: case-mix effects," American Journal of Kidney Diseases, vol. 44, no. 5, Supplement 2, pp. S16-S21, 2004.

[17] L. Finelli, J. T. Miller, J. I. Tokars, M. J. Alter, and M. J. Arduino, "National surveillance of dialysis-associated diseases in the United States, 2002," Seminars in Dialysis, vol. 18, no. 1, pp. 52-61, 2005.

[18] A. A. Qadi, H. Tamim, G. Ameen et al., "Hepatitis B and hepatitis $\mathrm{C}$ virus prevalence among dialysis patients in Bahrain and Saudi Arabia: a survey by serologic and molecular methods," American Journal of Infection Control, vol. 32, no. 8, pp. 493-495, 2004.

[19] M. Chandra, M. N. Khaja, M. M. Hussain et al., "Prevalence of hepatitis B and hepatitis C viral infections in Indian patients with chronic renal failure," Intervirology, vol. 47, no. 6, pp. 374-376, 2004.

[20] S. Chattopadhyay, S. Rao, B. C. Das, N. P. Singh, and P. Kar, "Prevalence of transfusion-transmitted virus infection in patients on maintenance hemodialysis from New Delhi, India," Hemodialysis International, vol. 9, no. 4, pp. 362-366, 2005.

[21] F. J. Carrilho, C. R. Moraes, J. R. R. Pinho et al., "Hepatitis $B$ virus infection in Haemodialysis Centres from Santa Catarina State, Southern Brazil. Predictive risk factors for infection and molecular epidemiology," BMC Public Health, vol. 27, pp. 4-13, 2004.

[22] N. Igaki, M. Nakaji, R. Moriguchi et al., "An outbreak of fulminant hepatitis B in immunocompromised hemodialysis patients," Journal of Gastroenterology, vol. 38, no. 10, pp. 968976, 2003.

[23] F. Fabrizi, P. Martin, V. Dixit, S. Bunnapradist, and G. Dulai, "Meta-analysis: the effect of age on immunological response to hepatitis B vaccine in end-stage renal disease," Alimentary Pharmacology and Therapeutics, vol. 20, no. 10, pp. 10531062, 2004.

[24] C. E. Stevens, H. J. Alter, P. E. Taylor et al., "Hepatitis B vaccine in patients receiving hemodialysis," New England Journal of Medicine, vol. 311, no. 8, pp. 496-501, 1984.
[25] G. Vagelli, G. Calabrese, A. Mazzotta, G. Pratesi, and M. Gonella, "More about response to hepatitis B vaccine in hemodialysis patients," Nephron, vol. 49, no. 2, p. 171, 1988.

[26] E. Fernández, M. A. Betriu, R. Gómez, and J. Montoliu, "Response to the hepatitis B virus vaccine in haemodialysis patients: influence of malnutrition and its importance as a risk factor for morbidity and mortality," Nephrology Dialysis Transplantation, vol. 11, no. 8, pp. 1559-1563, 1996.

[27] J. F. Navarro, J. L. Teruel, M. L. Mateos, R. Marcen, and J. Ortuño, "Antibody level after hepatitis B vaccination in hemodialysis patients: influence of hepatitis $\mathrm{C}$ virus infection," American Journal of Nephrology, vol. 16, no. 2, pp. 9597, 1996.

[28] T. S. Ahuja, S. Kumar, H. Mansoury, H. Rodriguez, and Y. F. Kuo, "Hepatitis B vaccination in human immunodeficiency virus-infected adults receiving hemodialysis," Kidney International, vol. 67, no. 3, pp. 1136-1141, 2005.

[29] F. Fabrizi, S. Di Filippo, D. Marcelli et al., "Recombinant hepatitis B vaccine use in chronic hemodialysis patients: longterm evaluation and cost-effectiveness analysis," Nephron, vol. 72, no. 4, pp. 536-543, 1996.

[30] S. Pol, C. Legendre, B. Mattlinger, P. Berthelot, and H. Kreis, "Genetic basis of nonresponse to hepatitis B vaccine in hemodialyzed patients," Journal of Hepatology, vol. 11, no. 3, pp. 385-387, 1990.

[31] J. J. Sennesael, P. Van der Niepen, and D. L. Verbeelen, "Treatment with recombinant human erythropoietin increases antibody titers after hepatitis B vaccination in dialysis patients," Kidney International, vol. 40, no. 1, pp. 121-128, 1991.

[32] M. M. Jibani, J. Heptonstall, A. M. Walker, L. O. Bloodworth, and A. J. Howard, "Hepatitis B immunization in UK renal units: failure to put policy into practice," Nephrology Dialysis Transplantation, vol. 9, no. 12, pp. 1765-1768, 1994.

[33] F. Fabrizi, S. V. Ganeshan, V. Dixit, and P. Martin, "Metaanalysis: the adjuvant role of granulocyte macrophage-colony stimulating factor on immunological response to hepatitis B virus vaccine in end-stage renal disease," Alimentary Pharmacology and Therapeutics, vol. 24, no. 5, pp. 789-796, 2006.

[34] P. Urbánek, "Viral hepatitis infections in chronic kidney disease patients and renal transplant recipients," Kidney and Blood Pressure Research, vol. 35, no. 6, pp. 454-467, 2012.

[35] R. J. Schroth, C. A. Hitchon, J. Uhanova et al., "Hepatitis B vaccination for patients with chronic renal failure," Cochrane Database of Systematic Reviews, no. 3, article CD003775, 2004.

[36] K. A. Barraclough and E. G. Playford, "Hepatitis B virus infection in hemodialysis populations: progress toward prevention," Kidney International, vol. 77, no. 3, pp. 177-180, 2010.

[37] M. Rizzetto, M. G. Canese, and S. Arico, "Immunofluorescence detection of new antigen-antibody system $(\delta /$ anti- $\delta)$ associated to hepatitis B virus in liver and in serum of HBsAg carriers," Gut, vol. 18, no. 12, pp. 997-1003, 1977.

[38] M. Rizzetto, M. G. Canese, and J. L. Gerin, "Transmission of the hepatitis B virus-associated delta antigen to chimpazees," Journal of Infectious Diseases, vol. 141, no. 5, pp. 590-602, 1980.

[39] J. Sheldon, B. Ramos, C. Toro et al., "Does treatment of hepatitis $\mathrm{B}$ virus (HBV) infection reduce hepatitis delta virus (HDV) replication in HIV-HBV-HDV-coinfected patients?" Antiviral Therapy, vol. 13, no. 1, pp. 97-102, 2008. 
[40] J. C. Carmo-Fonseca, "Hepatitis D," Revista da Sociedade Brasileira de Medicina Tropical, vol. 35, pp. 190-191, 2002.

[41] M. Rizzetto, B. Hoyer, and M. G. Canese, " $\delta$ agent: association of $\delta$ antigen with hepatitis B surface antigen and RNA in serum of $\delta$-infected chimpanzees," Proceedings of the National Academy of Sciences of the United States of America, vol. 77, no. 10, pp. 6124-6128, 1980.

[42] R. A. Burdick, J. L. Bragg-Gresham, J. D. Woods et al., "Patterns of hepatitis B prevalence and seroconversion in hemodialysis units from three continents: the DOPPS," Kidney International, vol. 63, no. 6, pp. 2222-2229, 2003.

[43] Z. Abbas, W. Jafri, and S. Raza, "Hepatitis D: scenario in the Asia-Pacific region," World Journal of Gastroenterology, vol. 16, no. 5, pp. 554-562, 2010.

[44] A. Karimi, S. Amini, and A. Amirkhani, "Investigation and Comparison of hepatitis D prevalence in dialysis patients and the donors of HBsAg carrier," Teb va Tazkie, vol. 36, pp. 30$35,2000$.

[45] M. H. Somi, S. Farhang, S. M. Miri, A. A. Pouri, G. Mjidi, and S. M. Alavian, "The frequency of hepatitis D virus in patients with hepatitis B in Iran: an increasing rate?" Tropical Doctor, vol. 39, no. 3, pp. 154-156, 2009.

[46] S. Krugman, J. P. Giles, and J. Hammond, "Viral hepatitis, type B (MS-2 strain) prevention with specific hepatitis B immune serum globulin," Journal of the American Medical Association, vol. 218, no. 11, pp. 1665-1670, 1971.

[47] E. B. Buynak, R. R. Roehm, A. A. Tytell, A. U. Bertland 2nd. A.U., G. P. Lampson, and M. R. Hilleman, "Vaccine against human hepatitis B," Journal of the American Medical Association, vol. 235, no. 26, pp. 2832-2834, 1976.

[48] B. J. McMahon, C. Helminiak, R. B. Wainwright, L. Bulkow, B. A. Trimble, and K. Wainwright, "Frequency of adverse reactions to hepatitis B vaccine in 43,618 persons," American Journal of Medicine, vol. 92, no. 3, pp. 254-256, 1992.

[49] S. Assad and A. Francis, "Over a decade of experience with a yeast recombinant hepatitis B vaccine," Vaccine, vol. 18, no. 1-2, pp. 57-67, 1999.

[50] D. R. Snydman, J. A. Bryan, E. J. Macon, and M. B. Gregg, "Hemodialysis associated hepatitis: report of an epidemic with further evidence on mechanisms of transmission," American Journal of Epidemiology, vol. 104, no. 5, pp. 563570, 1976.

[51] M. Carl, D. P. Francis, and J. E. Maynard, "A common source outbreak of hepatitis B in a hemodialysis unit," Dialysis and Transplantation, vol. 12, no. 4, pp. 222-229, 1983.

[52] M. J. Alter, J. Ahtone, and J. E. Maynard, "Hepatitis B virus transmission associated with a multiple-dose vial in a hemodialysis unit," Annals of Internal Medicine, vol. 99, no. 3, pp. 330-333, 1983.

[53] M. T. Niu, L. T. Penberthy, M. J. Alter, C. W. Armstrong, G. B. Miller, and S. C. Hadler, "Hemodialysis-associated hepatitis B: report of an outbreak," Dialysis and Transplantation, vol. 18, no. 10, pp. 542-555, 1989.

[54] W. T. London, J. S. Drew, and E. D. Lustbader, "Host responses to hepatitis B infection in patients in a chronic hemodialysis unit," Kidney International, vol. 12, no. 1, pp. 51-58, 1977.

[55] N. K. C. Tong, J. Beran, S. A. Kee et al., "Immunogenicity and safety of an adjuvanted hepatitis B vaccine in prehemodialysis and hemodialysis patients," Kidney International, vol. 68, no. 5, pp. 2298-2303, 2005.

[56] H. Sorkhi, M. R. H. Roushan, G. H. Al Hashemi, M. R. E. Dooki, and S. Bai, "Response to hepatitis B virus vaccination in haemodialysis patients with and without hepatitis C infection," Eastern Mediterranean Health Journal, vol. 14, no. 4, pp. 798-803, 2008.

[57] A. Miłkowski, G. Wyrwicz, P. Kubit, and O. Smoleński, "Comparison of anti-HBV vaccine efficacy given intradermally and intramuscularly in hemodialysis patients," Przeglad Lekarski, vol. 57, no. 11, pp. 628-634, 2000.

[58] Centers for Disease Control, "Recommendations for preventing transmission of infections among chronic hemodialysis patients," Morbidity and Mortality Weekly Report, vol. 50, no. RR-5, pp. 1-43, 2001.

[59] R. K. Gupta and G. R. Siber, "Adjuvants for human vaccines. Current status, problems and future prospects," Vaccine, vol. 13, no. 14, pp. 1263-1276, 1995.

[60] D. T. O’Hagan and E. De Gregorio, “The path to a successful vaccine adjuvant_- "The long and winding road"'” Drug Discovery Today, vol. 14, no. 11-12, pp. 541-551, 2009.

[61] M. L. Mbow, E. De Gregorio, N. M. Valiante, and R. Rappuoli, "New adjuvants for human vaccines," Current Opinion in Immunology, vol. 22, no. 3, pp. 411-416, 2010.

[62] P. Rizza, M. Ferrantini, I. Capone, and F. Belardelli, "Cytokines as natural adjuvants for vaccines: where are we now?" Trends in Immunology, vol. 23, no. 8, pp. 381-383, 2002.

[63] S. M. Santini, T. Di Pucchio, C. Lapenta, S. Parlato, M. Logozzi, and F. Belardelli, "The natural alliance between type I interferon and dendritic cells and its role in linking innate and adaptive immunity," Journal of Interferon and Cytokine Research, vol. 22, no. 11, pp. 1071-1080, 2002.

[64] A. Le Bon, G. Schiavoni, G. D’Agostino, I. Gresser, F. Belardelli, and D. F. Tough, "Type I interferons potently enhance humoral immunity and can promote isotype switching by stimulating dendritic cells in vivo," Immunity, vol. 14, no. 4, pp. 461-470, 2001.

[65] L. Bracci, I. Canini, S. Puzelli et al., "Type I IFN is a powerful mucosal adjuvant for a selective intranasal vaccination against influenza virus in mice and affects antigen capture at mucosal level," Vaccine, vol. 23, no. 23, pp. 2994-3004, 2005.

[66] S. M. Santini, T. Di Pucchio, C. Lapenta, S. Parlato, M. Logozzi, and F. Belardelli, "A new type I IFN-mediated pathway for the rapid differentiation of monocytes into highly active dendritic cells," Stem Cells, vol. 21, no. 3, pp. 357-362, 2003.

[67] C. Lapenta, S. M. Santini, M. Logozzi et al., "Potent immune response against HIV-1 and protection from virus challenge in hu-PBL-SCID mice immunized with inactivated viruspulsed dendritic cells generated in the presence of IFN- $\alpha$," Journal of Experimental Medicine, vol. 198, no. 2, pp. 361367, 2003.

[68] M. E. Miquilena-Colina, T. Lozano-Rodríguez, L. GarcíaPozo et al., "Recombinant interferon- $\alpha 2 b$ improves immune response to hepatitis $\mathrm{B}$ vaccination in haemodialysis patients: results of a randomised clinical trial," Vaccine, vol. 27, no. 41, pp. 5654-5660, 2009.

[69] M. L. Disis, H. Bernhard, F. M. Shiota et al., "Granulocytemacrophage colony-stimulating factor: an effective adjuvant for protein and peptide-based vaccines," Blood, vol. 88, no. 1, pp. 202-210, 1996.

[70] S. Okamura, T. Tanaka, S. Yamaga, F. Omori, and Y. Niho, "The effects of recombinant human granulocytemacrophage colony-stimulating factor on the induction of lymphokine-activated killer cells in vitro," International Journal of Immunopharmacology, vol. 13, no. 5, pp. 587-593, 1991. 
[71] P. N. Jikki, G. Anuradha, and Joshi N. Narayen, "The efficacy of granulocyte macrophage-colony stimulating factor (GMCSF) as adjuvant to hepatitis B vaccine in patients of CRF," Indian Journal of Nephrology, vol. 8, pp. 134-135, 1998.

[72] K. Krishnamurthy, G. T. John, P. Abraham, and C. K. Jacob, "Granulocyte macrophage colony stimulating factor augmented hepatitis B vaccine protocol for rapid seroprotection in voluntary kidney donors," Indian Journal of Medical Research, vol. 119, no. 4, pp. 162-164, 2004.

[73] M. A. Verkade, J. Van De Wetering, M. Klepper, L. M. B. Vaessen, W. Weimar, and M. G. H. Betjes, "Peripheral blood dendritic cells and GM-CSF as an adjuvant for hepatitis B vaccination in hemodialysis patients," Kidney International, vol. 66, no. 2, pp. 614-621, 2004.

[74] R. Lin, P. E. Tarr, and T. C. Jones, "Present status of the use of cytokines as adjuvants with vaccines to protect against infectious diseases," Clinical Infectious Diseases, vol. 21, no. 6, pp. 1439-1449, 1995.

[75] G. Magnani, H. Lehndorff, and C. Calzetti, "Immune response to hepatits $\mathrm{B}$ vaccine and duration of the protection in a hemodialysis unit," Acta Biomedica de l'Ateneo Parmense, vol. 58, no. 1-2, pp. 41-47, 1987.

[76] M. Cruciani, C. Mengoli, G. Serpelloni, R. Mazzi, O. Bosco, and M. Malena, "Granulocyte macrophage colony-stimulating factor as an adjuvant for hepatitis B vaccination: a metaanalysis," Vaccine, vol. 25, no. 4, pp. 709-718, 2007.

[77] European Medicines Agency (EMEA), "European Public Assessment Reports (EPARs) for authorized medicinal products for human use," Fendrix. EPAR H-C-50, http:// www.emea.europa.eu/humandocs/Humans/EPAR/fendrix/ fendrix.htm.

[78] N. Garçon, P. Chomez, and M. Van Mechelen, "GlaxoSmithKline Adjuvant Systems in vaccines: concepts, achievements and perspectives," Expert Review of Vaccines, vol. 6, no. 5, pp. 723-739, 2007.

[79] N. C. T. Kong, J. Beran, S. A. Kee et al., "A new adjuvant improves the immune response to hepatitis B vaccine in hemodialysis patients," Kidney International, vol. 73, no. 7, pp. 856-862, 2008.

[80] P. Vandepapelière, Y. Horsmans, P. Moris et al., "Vaccine Adjuvant Systems containing monophosphoryl lipid A and QS21 induce strong and persistent humoral and T cell responses against hepatitis $\mathrm{B}$ surface antigen in healthy adult volunteers," Vaccine, vol. 26, no. 10, pp. 1375-1386, 2008.

[81] M. Surquin, C. L. Tielemans, I. Kulcsár et al., "Rapid, enhanced, and persistent protection of patients with renal insufficiency by AS02V-adjuvanted hepatitis B vaccine," Kidney International, vol. 77, no. 3, pp. 247-255, 2010.

[82] T. B. Drüeke, P. Bárány, M. Cazzola et al., "Management of iron deficiency in renal anemia: guidelines for the optimal therapeutic approach in erythropoietin-treated patients," Clinical Nephrology, vol. 48, no. 1, pp. 1-8, 1997.

[83] D. Vlassopoulos, "Recombinant hepatitis B vaccination in renal failure patients," Current Pharmaceutical Biotechnology, vol. 4, no. 2, pp. 141-151, 2003.

[84] K. Blackwell, P. Gascón, G. Sigounas, and L. Jolliffe, "rHuEPO and improved treatment outcomes: potential modes of action," Oncologist, vol. 9, supplement 5, pp. 41-47, 2004.

[85] G. Weiss and V. R. Gordeuk, "Benefits and risks of iron therapy for chronic anaemias," European Journal of Clinical Investigation, Supplement, vol. 35, no. 3, pp. 36-45, 2005.
[86] J. H. Liu, Y. L. Liu, H. H. Lin et al., "Intravenous iron attenuates postvaccination anti-HBsAg titres after quadruple hepatitis $B$ vaccination in dialysis patients with erythropoietin therapy," International Journal of Clinical Practice, vol. 63, no. 3, pp. 387-393, 2009.

[87] E. S. Kimball, "Experimental modulation of IL-1, production and cell surface molecule expression by levamisole," Annals of the New York Academy of Sciences, vol. 685, pp. 259-268, 1993.

[88] R. F. Holcombe, A. Li, and R. M. Stewart, "Levamisole and interleukin-2 for advanced malignancy," Biotherapy, vol. 11, no. 4, pp. 255-258, 1998.

[89] C. C. Szeto, K. M. Gillespie, and P. W. Mathieson, "Levamisole induces interleukin-18 and shifts type 1/type 2 cytokine balance," Immunology, vol. 100, no. 2, pp. 217-224, 2000.

[90] J. A. Johnkoski, S. M. Peterson, R. J. Doerr, and S. A. Cohen, "Levamisole regulates the proliferation of murine liver T cells through Kupffer-cell-derived cytokines," Cancer Immunology Immunotherapy, vol. 43, no. 5, pp. 299-306, 1996.

[91] K. Katoch, "Immunotherapy of leprosy," Indian Journal of Leprosy, vol. 68, no. 4, pp. 349-361, 1996.

[92] S. Thoelen, N. De Clercq, and N. Tornieporth, "A prophylactic hepatitis B vaccine with a novel adjuvant system," Vaccine, vol. 19, no. 17-19, pp. 2400-2403, 2001.

[93] M. Ruiz-Moreno, R. Garcia, M. J. Rua et al., "Levamisole and interferon in children with chronic hepatitis B," Hepatology, vol. 18, no. 2, pp. 264-269, 1993.

[94] S. V. Grishchenko, L. A. Lavrukhina, and E. S. Ketiladze, "The results of combined therapy of patients with influenza complicated with pneumonia using levamisole," Voprosy Virusologii, vol. 29, no. 2, pp. 175-179, 1984.

[95] R. F. Holcombe, C. E. McLaren, and T. Milovanovic, "Immunomodulation with low dose levamisole in patients with colonic polyps," Cancer Detection and Prevention, vol. 30, no. 1, pp. 94-98, 2006.

[96] W. Schippinger, M. Jagoditsch, C. Sorré et al., "A prospective randomised trial to study the role of levamisole and interferon alfa in an adjuvant therapy with 5-FU for stage III colon cancer," British Journal of Cancer, vol. 92, no. 9, pp. 16551662, 2005.

[97] M. Rizzetto, "Therapy for chronic hepatitis B. Present status," Minerva Gastroenterologica e Dietologica, vol. 46, no. 1, pp. 16, 2000.

[98] S. M. Alavian and S. V. Tabatabaei, "Effects of oral levamisole as an adjuvant to hepatitis B vaccine in adults with end-stage renal disease: a meta-analysis of controlled clinical trials," Clinical therapeutics, vol. 32, no. 1, pp. 1-10, 2010.

[99] F. Ambrosch, G. Wiedermann, F. E. Andre et al., "Clinical and immunological investigation of a new combined hepatitis A and hepatitis B vaccine," Journal of Medical Virology, vol. 44, no. 4, pp. 452-456, 1994.

[100] A. Knöll, B. Hottenträger, J. Kainz, B. Bretschneider, and W. Jilg, "Immunogenicity of a combined hepatitis A and B vaccine in healthy young adults," Vaccine, vol. 18, no. 19, pp. 2029-2032, 2000.

[101] Engerix-B Product Monograph, GlaxoSmithKline, 2005.

[102] E. L. Pesanti, "Immunologic defects and vaccination in patients with chronic renal failure," Infectious Disease Clinics of North America, vol. 15, no. 3, pp. 813-832, 2001.

[103] Centers for Disease Control, "Recommendationsfor preventing transmission of infections among chronic hemodialysis patients," Morbidity and Mortality Weekly Report, vol. 50, no. RR-5, pp. 1-43, 2001. 
[104] S. Sezer, F. N. Özdemir, G. Güz et al., "Factors influencing response to hepatitis B virus vaccination in hemodialysis patients," Transplantation Proceedings, vol. 32, no. 3, pp. 607$608,2000$.

[105] G. H. Mayor, A. M. Klein, T. J. Kelly, and M. J. Patterson, "Antibody to hepatitis A and hemodialysis," American Journal of Epidemiology, vol. 116, no. 5, pp. 821-827, 1982.

[106] J. Tung, E. Carlisle, M. Smieja, P. T. Kim, and C. H. Lee, "A randomized clinical trial of immunization with combined hepatitis A and B versus hepatitis B alone for hepatitis B seroprotection in hemodialysis patients," American Journal of Kidney Diseases, vol. 56, no. 4, pp. 713-719, 2010.

[107] A. Shavakhi, M. H. Somi, S. Farhang, G. Majidi, and T. Majidi, "Pouri AAPrevalence of hepatitis A in Iranian patients with chronic liver disease," Iranian Journal of Clinical Infectious Diseases, vol. 3, pp. 189-192, 2008.

[108] M. C. Rangel, V. G. Coronado, G. L. Euler, and R. A. Strikas, "Vaccine recommendations for patients on chronic dialysis," Seminars in Dialysis, vol. 13, no. 2, pp. 101-107, 2000.

[109] J. A. Quiroga and V. Carreno, "Interferon and hepatitis B vaccine in haemodialysis patients," The Lancet, vol. 1, no. 8649, p. $1264,1989$.

[110] F. Fabrizi, S. Andrulli, G. Bacchini, M. Corti, and F. Locatelli, "Intradermal versus intramuscular hepatitis B re-vaccination in non-responsive chronic dialysis patients: a prospective randomized study with cost-effectiveness evaluation," Nephrology Dialysis Transplantation, vol. 12, no. 6, pp. 1204-1211, 1997.

[111] K. A. Barraclough, K. J. Wiggins, C. M. Hawley et al., "Intradermal versus intramuscular Hepatitis B vaccination in hemodialysis patients: a prospective open-label randomized controlled trial in nonresponders to primary vaccination," American Journal of Kidney Diseases, vol. 54, no. 1, pp. 95103, 2009. 


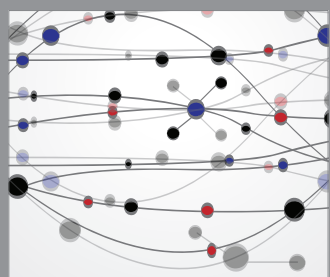

The Scientific World Journal
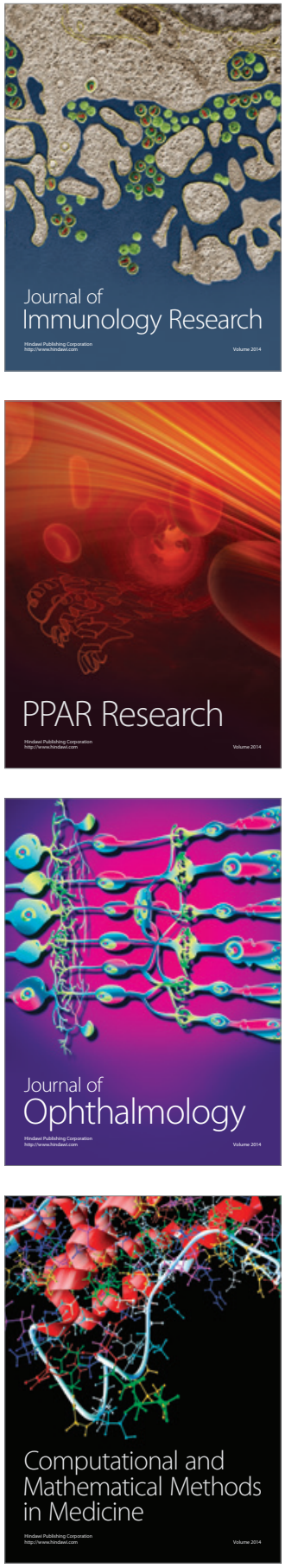

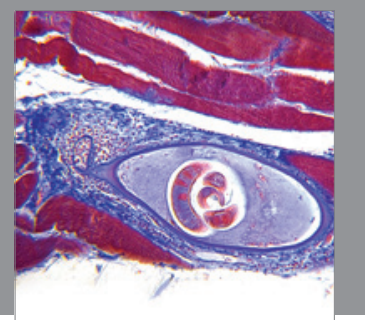

Gastroenterology

Research and Practice
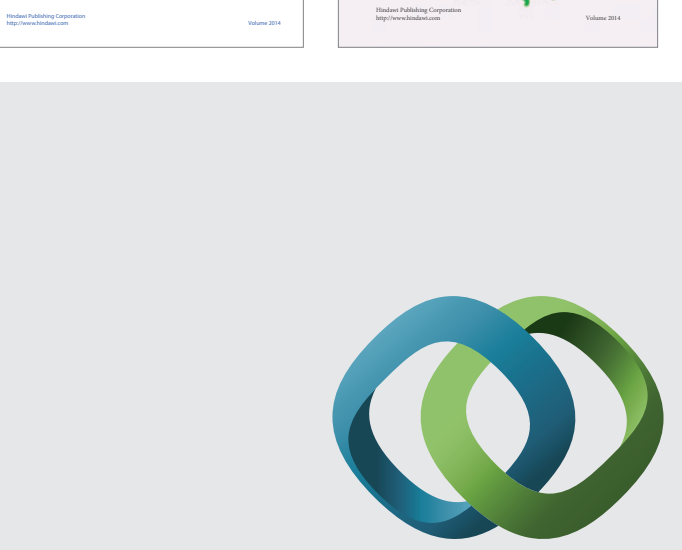

\section{Hindawi}

Submit your manuscripts at

http://www.hindawi.com
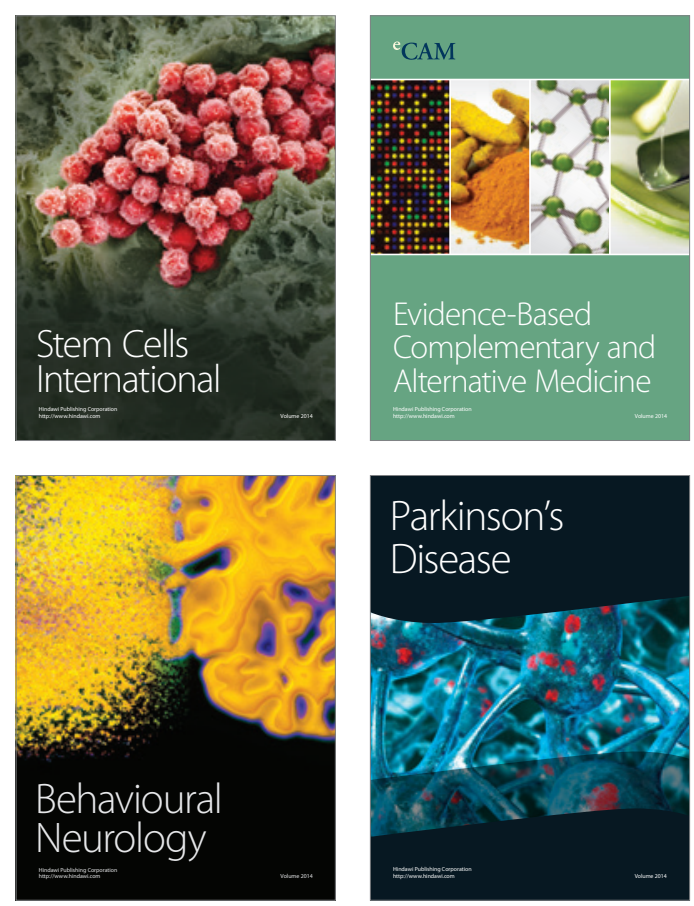

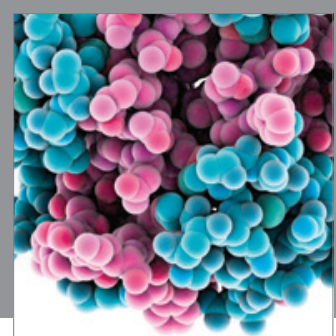

Journal of
Diabetes Research

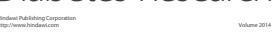

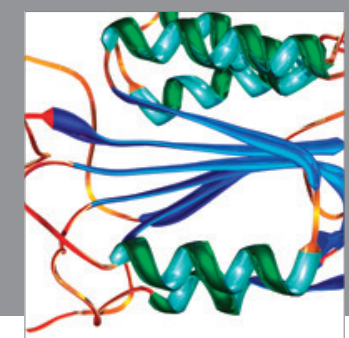

Disease Markers
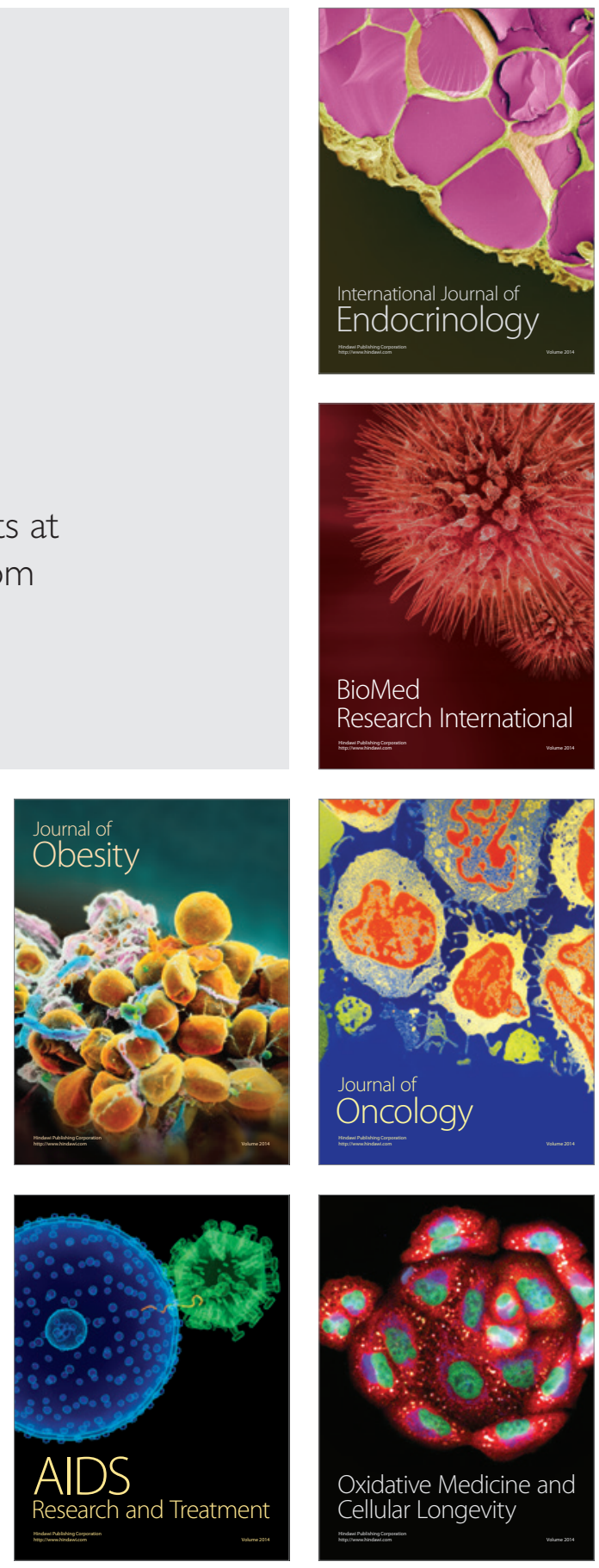